are unwilling to tackle risky but necessary procedures or prefer early retirement to the stress of practice and patients or the NHS are unable to afford the cost of treatment.

Dr Baker's paper states that there were 510 charges in a five-year period [an average of 102 per annum]. I understand that the GDC had paid for advertisements seeking complaints. This must surely be a misuse of registrants' fees as it encourages rogue lawyers to pursue fictitious claims.

According to statistics, in the five-year period 2013-17 there was an average of over 45,000 registered dentists. My geriatric maths makes the charges around $0.011 \%$ or one registrant for every 900 over five years. This is remarkably low compared to the performance of the Crown Prosecution Service or the record of MPs. The paper itself puts credit card fraud at 8.3\%.

NHS Dental Statistics for England 2016-17 state that there were 39.9 million courses of treatment provided by 24,007 dentists who had performed NHS activity. Assuming that none of the average 102 charges applied to non-NHS practice [ignoring the many registrants in hospital, community service and private practice] this suggests that the incidence of charges is around 1:40,000 courses of treatment [ignoring the number of privately provided courses]. Whilst I do not condone malpractice in any form, I believe that these figures will stand comparison with any group including ministers of religion.

Accepting that human frailty makes zero risk unattainable, Dr Baker's paper fails to address the level at which over regulation becomes counter-productive.

There is another aspect of the GDC's activity that is not addressed in this paper. During my professional life, I have encountered many excellent dentists who, for valid reasons, have needed to practice on a part-time basis. They have made a valuable contribution to their communities. However, when the cost of registration, insurance and continuing professional development becomes excessive, part-time work is no longer viable and their skills and service are lost. This is not in the public interest.

Whilst Dr Baker concentrates his defence on the GDC and Dr Moyes, the BDA has to take account of the totality of regulation which continually grows. The latest concerns data protection. The burden of regulation appears to be becoming unmanageable in small practices. The future may belong to big corporates who can afford the fees of legally trained personnel to manage their compliance obligations. But would the closure of small practices be in the public interest? Perhaps in reappointing Dr Moyes, the Government has signalled that this is their objective? It may seem perverse but in condoning the excessive expenditure of the GDC, the Department of Health and Social Care allows more of the NHS budget to be diverted to non-clinical expenditure.

Dr Baker disparages the 'good old days'. My first six months in 'cons' was with a foot engine. Post-war scarcity ensured that there was much 'make do and mend'. There was no alternative to the hot water steriliser and I was amongst the first to use zylocaine. We treated AUG with chromic acid and hydrogen peroxide because today's medication was not available.

Not all new techniques have been successful. Inevitably there will be a period in which the new replaces the old. Perhaps we should remember that it is not the equipment which we use that matters but the manner in which we use it. In the 'good old days' we provided an essential service with equipment and materials that were the best available at the time. Today we would be 'struck off'.

I agree that all practices should update their equipment when necessary but to do so they need to be adequately funded. Money spent on registration and compliance with regulations cannot be used to upgrade equipment.

I must disagree with Dr Baker's criticism of you, sir! He suggests that you should 'moderate' controversy. Is this not an attempt to introduce censorship? Maybe this was acceptable 'in the good old days' but surely we are now mature enough to allow you to publish opinion papers that fully express the individual's opinions providing they are relevant to the Journal and are within the bounds of decency and legality.

It is also suggested that 'we should change our negotiators'. I believe that it is the duty of our negotiators to represent the views and needs of our members. We should respect the offices held but those who hold them must earn the respect.

The BDA negotiators are representing the views of the many members who are, it appears to me, convinced that the GDC is not working in the best interests of the community and is 'not working with dentists'.

A. Green, by email

1. Baker R A. Cause for concern: BDA v GDC. Br Dent J 2018; 224: 769-776.

DOI: $10.1038 /$ sj.bdj.2018.654

\section{Sense of humour?}

Sir, I have very much enjoyed your past two good humoured BDJ Christmas editions, and having seen the 'call to arms' for items for this year's, wondered how I (and presumably many others, since there was only one submission) could have missed the same request for your 'Midsummer Madness' edition?

However, it is quality, not quantity, that counts and the Opinion article ${ }^{1}$ from $\mathrm{Mr}$ Baker certainly fitted the bill, with his wonderfully bizarre examples.

My absolute favourite was: 'The GDC has attempted to cut costs, for example it cut catering costs in 2001-2 by $42 \%$.'

He also references the 'Charlie and Rufus' videos and through your pages, I wonder if their editor, Mr Mike Wilson, could be persuaded out of retirement to do one more episode 'Dr Baker and the ARF solution'?

A. Lockyer, by email

1. Baker R A. Cause for concern: BDA v GDC. Br Dent J 2018; 224: 769-776.

DOI: 10.1038/sj.bdj.2018.655

\section{Oral surgery}

\section{Labial frenectomy: Indications and practical implications}

Sir, orthodontic and oral surgery departments are becoming inundated with unnecessary referrals from dentists, and sometimes orthodontic specialists, requesting upper labial frenectomies.

The age ranges vary, with some practitioners referring children in the primary dentition, which is illogical. Alternatively, referrals are for patients in the mixed dentition developmental stage with physiological spacing (sometimes referred to as the 'ugly duckling stage' of dental development - a term best avoided for obvious reasons).

The presence of a diastema less than approximately $2 \mathrm{~mm}$ may be considered normal at this stage of dental development, with the diastema often closing spontaneously upon eruption of the maxillary canines.

Neither the presence of an upper labial frenum, nor a maxillary dental midline diastema, is in itself an indication for a frenectomy. This is the case even when pulling the upper lip away from the dentoalveolus leads to visualisation of blanching in the palatal mucosa. This blanching is an indication that fibrous tissue from the labial frenum is passing between the central incisors, usually through an alveolar notch in 